\title{
Motivational Interviewing in Medical Settings
}

\author{
Ken Resnicow, Ph.D.' and David Blackburn, MALD ${ }^{2}$ \\ I University of Michigan School of Public Health, Ann Arbor, MI \\ 2 Executive Director, Nutrition \& Health Partnership, Wellesley Hills, MA
}

\section{Introduction}

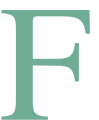

or many clinicians, the prospect of bringing up the topic of body weight and the associated behaviors of eating and physical activity can be daunting. On one hand, the clinician risks alienating the patient by bringing up a potentially sensitive subject; and on the other hand, given the limitations of time and the difficulty in making behavior changes in the best of circumstances, this can feel like a futile effort.

A July 2000 analysis of 55,858 adult physician office visits suggests that physicians reported obesity in only $38 \%$ of their obese patients. Physicians provided counseling only for weight loss $(35.5 \%)$, exercise $(32.8 \%)$, and diet $(41.5 \%)$ in their obese patients. Although patients with obesity-related comorbidities were treated more aggressively, weight-loss counseling still only occurred at only $52 \%$ of the visits in these patients. ${ }^{1}$ In a 1999 survey of nearly 13,000 obese adults, only $42 \%$ reported that their health professional advised them to lose weight during a routine physical examination. ${ }^{2}$

In a recent survey on the attitudes and practices regarding pediatric obesity, only $3.6 \%$ of physicians in New England $(\mathrm{N}=1243)$ reported feeling "quite confident" in counseling their obese patients. ${ }^{3}$ Poor patient

\section{Table I. Barriers to Treatment of Pediatric Obesity 4}

\begin{tabular}{|c|c|c|}
\hline & $\begin{array}{l}\text { Family Practice } \\
\text { Physicians }(n=74)\end{array}$ & $\begin{array}{l}\text { Pediatricians } \\
(n=213)\end{array}$ \\
\hline Lack of patient motivation & $99 \%$ & $97 \%$ \\
\hline Poor patient compliance & $96 \%$ & $95 \%$ \\
\hline Lack of effective therapy & $83 \%$ & $78 \%$ \\
\hline No insurance for referrals & $74 \%$ & $67 \%$ \\
\hline $\begin{array}{l}\text { Lack of availability of } \\
\text { referral services }\end{array}$ & $65 \%$ & $64 \%$ \\
\hline $\begin{array}{l}\text { No insurance for in-office } \\
\text { counseling }\end{array}$ & $60 \%$ & $51 \%$ \\
\hline $\begin{array}{l}\text { No time for frequent } \\
\text { follow-up }\end{array}$ & $56 \%$ & $49 \%$ \\
\hline
\end{tabular}

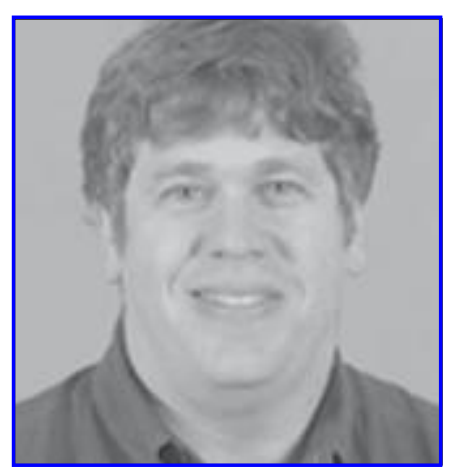

Ken Resnicow, Ph.D

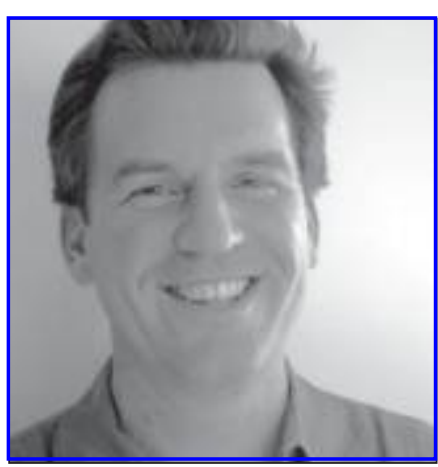

David Blackburn, MALD motivation, patient noncompliance, and treatment futility were perceived as the most frequently encountered barriers to pediatric obesity treatment among 339 pediatric and family physicians (Table 1). Less than half reported having even an "average" ability to counsel ${ }^{4}$ (Table 2).

Yet, given the well-understood relationship between excess body weight and many chronic diseases, it is a topic that cannot be ignored by medical professionals. This article provides a brief description of Motivational

\section{Only 3.6\% of physicians in New England report feeling "quite confident" in counseling obese patients.}

Interviewing (MI) and some of the tools and techniques that may provide effective strategies for addressing issues of body weight in brief counseling sessions in a medical setting. 


\begin{tabular}{|c|c|c|}
\hline \multicolumn{3}{|c|}{$\begin{array}{l}\text { Table 2. Attitudes Toward } \\
\text { Pediatric Obesity Counseling } 4\end{array}$} \\
\hline $\begin{array}{l}\text { Personal ability to } \\
\text { counsel } \\
\text { Poor }\end{array}$ & $\begin{array}{c}\text { Family Practice } \\
\text { Physicians }(n=74) \\
11 \%\end{array}$ & $\begin{array}{c}\text { Pediatricians } \\
(\mathrm{n}=213) \\
6 \%\end{array}$ \\
\hline Fair & $30 \%$ & $17 \%$ \\
\hline Average & $44 \%$ & $47 \%$ \\
\hline Good & $15 \%$ & $27 \%$ \\
\hline Excellent & $0 \%$ & $3 \%$ \\
\hline \multicolumn{3}{|c|}{ Efficacy of obesity counseling } \\
\hline Poor & $11 \%$ & $23 \%$ \\
\hline Fair & $48 \%$ & $33 \%$ \\
\hline Average & $36 \%$ & $35 \%$ \\
\hline Good & $5 \%$ & $9 \%$ \\
\hline Excellent & $0 \%$ & $0.5 \%$ \\
\hline
\end{tabular}

\section{The Spirit and Process of Ml}

MI is a counseling technique that was initially developed to treat addictions. It has increasingly been used to modify diet and physical activity behaviors. Emerging evidence shows that MI may be effective in modifying chronic disease behaviors. ${ }^{5-8}$ An essential element of MI is assisting individuals to work through "ambivalence" about behavior change and helping them to explore how their current health behavior affects their ability to achieve their goals or to live out their "core values." MI appears to be particularly effective for individuals who are initially less ready to change. ${ }^{9-13}$

The spirit of MI is a nonjudgmental, empathetic, and encouraging approach whereby patients feel comfortable expressing both the positive and negative aspects of any current behavior. Unlike traditional patient education that focuses on providing information, in MI the patient is expected to do much of the work and to do most of the talking. Physicians, nurses, and dietitians have traditionally been trained to provide expert advice about the benefits of health behavior change; ${ }^{14}$ however, in MI, little

\section{The spirit of $\mathrm{Ml}$ is a nonjudgmental, empathetic, and encouraging approach.}

effort is made to dismantle denial, to confront irrational beliefs, or to convince or persuade. Instead, the goal is to help patients to think about and to verbally express their own reasons both for and against change; how their cur- rent health behavior may conflict with their health goals; and how their current behavior or health status affects their ability to achieve their life goals or to live out their core values. The spirit of MI is that behavior change should be "negotiated" and not prescribed. Advice, persuasion, and even information can elicit as much resistance as they do change.

The mixture of pros and cons felt about making any behavior change is defined as "ambivalence" and is considered to be a normal state for most individuals as they contemplate behavior change. It is the challenge of the practitioner to facilitate the expression and eventual resolution of this ambivalence. A core principle of MI is that individuals are more likely to accept and to act upon that which they voice. ${ }^{15}$ The assumption is that behavior change is affected more by motivation than by information. A goal of MI is to encourage patients to make fully informed and deeply contemplated life choices, even if the decision is not to change. To achieve these ends, MI practitioners rely heavily on a number of core techniques, some of the most important of which are briefly described below.

\section{Agenda Setting and Asking Permission}

To ensure that patients are active and willing participants in the conversation about any given topic, they are asked to help set the agenda. This may include deciding what behaviors to talk about and what goals they have for the session or for the intervention in general. If there are multiple behaviors on which to focus, the agenda setting may prioritize which behaviors to work on and in what order. Permission is sought at key transitional points to ensure that the patient is continually engaged. For example, the practitioner may ask permission to provide information, to list possible solutions, or to discuss the patient's next step. Asking the patient's permission to talk about a subject is the equivalent to knocking on the examination room door before entering and can be an important and easy way to foster rapport between the patient and clinician.

\section{Reflective Listening}

Reflective listening involves "reflecting" back to the patient an accurate synopsis of what the patient has communicated to the clinician without judgment or editorial. Reflections, particularly by practitioners who are new to the technique, often begin, "It sounds like you feel...." More skilled practitioners often phrase their reflections as more direct statements such as "You are having trouble with..." and leaving off the assumed "It sounds like...." The goals of reflecting include demonstrating that the practitioner has actually heard what the patient is saying and affirms the patient's thoughts, knowledge, and feelings. One of the most important elements of mastering 
MI is suppressing the tendency to respond with questions or advice rather than with pure reflections. Reflecting helps to ensure that the direction of the encounter remains patient-driven. For the patient to hear what he or she has said is an important part of the process of understanding that patient's beliefs, values and motivation.

\section{Allowing the Patient to Interpret Information}

In the traditional patient education paradigm, the health practitioner often provides information about the risks of continuing a behavior or the benefits of change, with the intent of persuasion. Statements may include the following: "This is very important for your health because..."; "This behavior poses great risk..."; or "It is essential that you change because...." Implicit in such statements is a judgment that the patient is doing something "wrong." In contrast, in MI, information is presented in a neutral manner, and the patient is asked to interpret what it means for that patient on a personal level. For example, rather than saying that "It is important for you to lose weight because it places you at great risk of having another heart attack", in MI the practitioner might say, "You may have heard that excess weight can increase a person's risk of having another heart attack, and I have seen this happen to several of my patients. What is important to me is how you think about this, and what you think the risks are for you." MI practitioners allow patients to process information and to find their own personal relevance.

\section{Rolling with Resistance}

Confronting patients often creates an environment of defensiveness and leads to poor therapeutic outcomes. ${ }^{16}$ MI practitioners avoid confrontation and attempt to "roll with resistance" rather than contest it. The MI encounter is likened to a dance more than to a wrestling match. ${ }^{17}$ For example, if a patient questions the association between his or her diet and the risk of disease, rather than stating facts to counter that belief the practitioner may simply provide opportunities for the patient to express any doubts that she or he may have. The practitioner may use a "negative reverse" and state, "It appears that you see no benefit in changing your diet." By exaggerating slightly the patient's doubt using a nonsarcastic, neutral tone, this may serve to "unstick" the entrenched patient by short-circuiting the "Yes, but" cycle. In any case, even when the patient is blatantly and factually incorrect, little gain will be achieved by a direct confrontation. This nonconfrontational approach will lead to the building of rapport and eventually to a relationship in which the patient seeks information from the clinician.

\section{Assessing Readiness and Eliciting Change Talk}

Given that a core principle of MI is that individuals are more likely to act upon behaviors and beliefs that they

\section{Recent Papers on Motivational Interviewing and Obesity-Related Issues}

Bennett JA, Perrin NA, Hanson G, et al. Healthy aging demonstration project: Nurse coaching for behavior change in older adults. Res Nurs Health 2005;28:187-197.

Carino JL, Coke L, Gulanick M. Using motivational interviewing to reduce diabetes risk. Prog Cardiovasc Nurs 2004;19:149-154.

Goldberg JH, Kiernan M. Innovative techniques to address retention in a behavioral weight-loss trial. Health Educ Res 2005;20:439-447.

Hecht J, Borrelli B, Breger RK, et al. Motivational interviewing in community-based research: Experience from the field. Ann Behav Med 2005;29(Suppl):29-34.

Huang N. Motivating patients to move. Aust Fam Phys 2005;34:413-417.

Kirk S, Scott BJ, Daniels SR. Pediatric obesity epidemic: Treatment options. J Am Diet Assoc 2005;105(5 Suppl 1):S44-S51.

Lange N, Tigges BB. Influence positive change with motivational interviewing. Nurse Pract 2005;30:44-53.

Rubak S, Sandbaek A, Lauritzen T, Christensen B. Motivational interviewing: A systematic review and meta-analysis. Br J Gen Pract 2005; 55:305-312.

actually voice, ${ }^{15}$ the more a person advocates for a behavior, the greater his or her commitment often becomes. Therefore, considerable effort is made to allow patients to express their own reasons and plans for change. This is referred to as eliciting self-motivational statements or "change talk."

In medical practice, one technique to elicit change talk is to ask, "On a scale from 0 to 10 (with 10 the highest), how important is it for you to .... [modify target behavior]?" This question is then followed up with: "On a scale from 0 to 10 (with 10 the highest), assuming you wanted

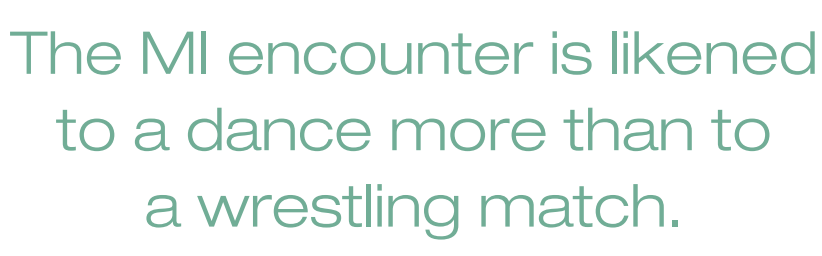

to change, how confident are you that you could...?" These questions are an effective way to gain a quick insight into the patient's readiness and efficacy for change. ${ }^{18,19}$ The first question could also ask about the willingness to change rather than the importance.

Using the patient's response, for example, " 5 " on the scale, the practitioner then asks: "Why did you not choose a lower number, like a 1 or 2?" The importance of choosing a lower number is that this elicits positive change talk. The practitioner then asks: "Why did you not choose a higher number?" which elicits barriers. 


\begin{tabular}{|c|c|}
\hline \multicolumn{2}{|c|}{$\begin{array}{c}\text { Table 3. Possible Core Values for } \\
\text { Adolescents } 20\end{array}$} \\
\hline Attractive & Independent \\
\hline Athletic & Mature \\
\hline Competent & On top of things \\
\hline Confident & Popular \\
\hline Disciplined & Respected at home \\
\hline Energetic & Respected at school \\
\hline Good student & Responsible \\
\hline Good to my parents & Spiritual \\
\hline Healthy and fit & Strong \\
\hline In control & Successful \\
\hline
\end{tabular}

When barriers are presented, the clinician prompts the patient to suggest his or her own solutions rather than offering solutions. To gain a deeper insight into possible sources of motivation, the clinician may further ask "What would it take to get you to a 9 or a 10 from where you are now"? When the patient responds with a 0 or 10 , the respective "lower" or "higher" probes are omitted.

\section{Identifying Discrepancies and Eliciting Change Talk}

Another method for evoking change talk is to help patients develop a discrepancy between their current behavior and their behavioral goals. For example, with patients who have expressed interest in changing a particular behavior but have not accomplished their stated goal, the practitioner may "softly explore" this discrepancy. This is accomplished with a low-key, inquisitive tone rather than by expressing disappointment or imparting guilt.

A related strategy is to help patients establish discrepancies between their current behavior and their "core" values or life goals. An important principle of MI is that the source of long-term motivation for any behavior change is in some way linked to an individual's core values. An abbreviated list of possible core values for an adolescent patient is provided in Table $3 .{ }^{20}$ After the values are identified, the clinician inquires whether the patient sees any connection between his or her health behaviors and the ability to achieve these goals or to realize these values. Alternatively, the clinician may ask how changing the health behavior would be related to these goals or values. The list of values and attributes can be tailored to the particular population or the health behavior being addressed. For example, the list for adolescents may include values such as "being popular" or "mature," whereas for an elder population the list may include values related to independent living, youth, or vitality. Alternatively, some practitioners obtain goals and values using openended questions rather than a list.

\section{Summary}

The process of changing many chronic disease behaviors generally involves modifying rather than eliminating the behavior-that is, reshaping rather than abstaining. These changes need to be made long term if not for a lifetime. An individual's ambivalence toward making any behavioral change may center on the longterm burden of change. Reducing or eliminating a favorite food or reducing preferred sedentary behaviors could be perceived as a major sacrifice, with reactions similar to withdrawal. MI, in such cases, may focus on helping people come to grips with the chronic nature of their conditions and identifying ways to reduce what might be perceived as an overwhelming burden. Thus, a key goal for an MI practitioner might be to help an individual reframe for herself or himself the change in positive terms (for example, what is gained versus what is lost) and to identify a source or motivation that can sustain these behavior changes.

There are important considerations related to feasibility and efficacy when using MI in medical settings. Perhaps the greatest challenge in using MI in medical settings is the limitations on time in settings in which patients are typically seen for 10 to 15 minutes. In fact, medical practitioners may have only a single contact with a patient to address that person's health behavior. Even when care is ongoing, it can be difficult to be reimbursed for behavioral counseling. For these reasons, in many of the health promotion and medical settings where MI is being applied, the quantity and quality of counseling may be quite different than other contexts. Rollnick et al ${ }^{21}$ have delineated a continuum model that delineates three levels of intervention:

- MI

- Behavior change counseling

- Brief advice

These differ not only in the skills involved but also in the context and purpose of the consultation. Brief advice can be used in a wide range of circumstances and with a large number of patients. Professionals can use this method with limited skills and training. Research is needed to examine whether this level of intervention is more effective than standard care in promoting behavior change.

Ultimately the essential question may not be whether MI works in medical settings but rather how well, in what populations, at what dose, and at what cost. The issues of which professions are best able to deliver MI with sufficient fidelity, and how much training is needed to raise competence to adequate levels, should be addressed. The questions of how different health care delivery systems (for example, public versus private hospitals; health 
maintenance organizations versus preferred provider plans) will be willing and able to incorporate MI into clinical practice, and how practitioners will be reimbursed for training and delivery of MI, merit examination.

\section{References}

1. Stafford RS, Farhat JH, Misra B, Schoenfeld DA. National patterns of physician activities related to obesity management. Arch Fam Med 2000;9:631-638.

2. Galuska DA, Will JC, Serdula MK, Ford ES. Are health care professionals advising obese patients to lose weight. JAMA 1999; 282:1576-1578.

3. Jelalian E, Boergers J, Alday CS, Frank R. Survey of physician attitudes and practices related to pediatric obesity. Clin Pediatr 2003;42:235-245.

4. Kolagotla L, Adams W. Ambulatory management of childhood obesity. Obes Res 2004;12:275-283.

5. Berg-Smith S, Stevens V, Brown K, et al. A brief motivational intervention to improve dietary adherence in adolescents. Health Educ Res 1999;14:399-410.

6. Mhurchu CN, Margetts BM, Speller V. Randomized clinical trial comparing the effectiveness of two dietary interventions for patients with hyperlipidaemia. Clin Sci 1998;95:479-487.

7. Smith D, Heckemeyer C, Kratt P, Mason D. Motivational interviewing to improve adherence to a behavioral weight-control program for older obese women with NIDDM. Diabetes Care 1997;20:52-54.

8. Woollard J, Beilin L, Lord T, et al. A controlled trial of nurse counselling on lifestyle change for hypertensives treated in general practice: preliminary results. Clin Exp Pharmacol Physiol 1995; 22:466-468.

9. Butler C, Rollnick S, Cohen D, et al. Motivational consulting versus brief advice for smokers in general practice: A randomized trial. $\underline{\mathrm{Br} \mathrm{J}}$ Gen Pract 1999;49:611-616.
10. Heather N, Rollnick S, Bell A, Richmond R. Effects of brief counselling among male heavy drinkers identified on general hospital wards. Drug Alcohol Rev 1996;15:29-38.

11. Miller W, Rollnick S. Motivational Interviewing: Preparing People to Change Addictive Behavior. New York: Guilford Press, 1991.

12. Resnicow $K$, Jackson A, Wang $T$, et al. A motivational interviewing intervention to increase fruit and vegetable intake through black churches: results of the Eat for Life Trial. Am J Public Health 2001;91: 1686-1693.

13. Rollnick S, Miller WR. What is motivational interviewing? Behav Cognitive Psychother 1995;23:325-334.

14. Goldstein M, DePue J, Monroe A, et al. A population-based survey of physician smoking cessation counseling practices. $\underline{\text { Prev Med }}$ 1998;27:720-729.

15. Bem D. Self-perception theory. In: L. Berkowitz (ed.), Advances in Experimental Social Psychology, Vol. 6. New York: Academic Press, 1972:1-62.

16. Miller WR. Motivational interviewing with problem drinkers. Behav Psychother 1983;11:147-172.

17. Rollnick S, Mason P, Butler C. Health Behavior Change: A Guide for Practitioners. London: Churchill Livingstone, 1999.

18. Rollnick S, Butler CC, Stott N. Helping smokers make decisions: The enhancement of brief intervention for general medical practice. Patient Educ Counsel 1997;31:191-203.

19. Rollnick S, Heather N, Gold R, Hall W. Development of a short "readiness to change" questionnaire for use in brief, opportunistic interventions among excessive drinkers. Br J Addict 1992;87:743-754.

20. Resnicow K, Jackson A, Braithwaite R, et al. Healthy Body/Healthy Spirit: Design and evaluation of a church-based nutrition and physical activity intervention using motivational interviewing. Health Educ Res 2002;17:562-573.

21. Rollnick S, Allison J, Ballasiotes S, et al. Variations on a Theme: Motivational Interviewing and Its Adaptations. In: Miller W, Rollnick $\mathrm{S}$ (eds.). Motivational Interviewing, ${ }^{2 n d}$ ed. New York: Guilford Press, 2002. 
This article has been cited by:

1. Susan Gallagher Camden . 2006. Nursing Care of the Bariatric PatientNursing Care of the Bariatric Patient. Bariatric Nursing and Surgical Patient Care 1:1, 21-30. [Abstract] [PDF] [PDF Plus] 